\title{
Brachyury gene copy number gain and activation of the PI3K/Akt pathway: association with upregulation of oncogenic Brachyury expression in skull base chordoma
}

\author{
Ryohei Otani, MD, PhD, ${ }^{1,2}$ Akitake Mukasa, MD, PhD, ${ }^{1}$ Masahiro Shin, MD, PhD, ${ }^{1}$ Mayu Omata, PhD, ${ }^{1}$ \\ Shunsaku Takayanagi, MD, PhD, ${ }^{1}$ Shota Tanaka, MD, ${ }^{1}$ Keisuke Ueki, MD, PhD, ${ }^{2}$ and \\ Nobuhito Saito, MD, PhD'1
}

1'Department of Neurosurgery, Graduate School of Medicine, The University of Tokyo; and ²Department of Neurosurgery, Dokkyo Medical University, Tochigi, Japan

\begin{abstract}
OBJECTIVE Chordoma is a slow-growing but clinically malignant tumor, and the prognosis remains poor in many cases. There is a strong impetus to develop more effective targeted molecular therapies. On this basis, the authors investigated the potential of Brachyury, a transcription factor involved in notochord development, as a candidate molecular target for the treatment of chordoma.
\end{abstract}

METHODS Brachyury gene copy number and expression levels were evaluated by quantitative polymerase chain reaction in 27 chordoma samples, and the transcriptomes of Brachyury high-expression tumors $(n=4)$ and Brachyury lowexpression tumors $(n=4)$ were analyzed. A chordoma cell line $(U-C H 2)$ was used to investigate the signaling pathways that regulate Brachyury expression.

RESULTS All chordoma specimens expressed Brachyury, and expression levels varied widely. Patients with higher Brachyury expression had significantly shorter progression-free survival ( 5 months, $n=11)$ than those with lower expression (13 months, $n=16)(p=0.03)$. Somatic copy number gain was confirmed in 12 of $27(44 \%)$ cases, and copy number was positively correlated with Brachyury expression $(R=0.61, p<0.001)$. Expression of $P I 3 K / A k t$ pathway genes was upregulated in Brachyury high-expression tumors, and suppression of PI3K signaling led to reduced Brachyury expression and inhibition of cell growth in the U-CH2 chordoma cell line.

CONCLUSIONS Activation of the PI3K/Akt pathway and Brachyury copy number gain are strongly associated with Brachyury overexpression, which appears to be a key event in chordoma growth regulation. These findings suggest that targeting Brachyury and PI3K/Akt signaling may be an effective new approach for treating chordoma.

https://thejns.org/doi/abs/10.3171/2016.12.JNS161444

KEY WORDS chordoma; brachyury; PI3K/Akt pathway; copy number; oncology; skull base

$\mathrm{C}$ HORDOMA is a rare tumor, with an incidence of 0.08 per 100,000 persons. ${ }^{6}$ The peak age of onset is in the $50 \mathrm{~s}$, and there is a slight male predominance..$^{5,17}$ Chordoma is presumed to originate from the embryonic notochord, which is involved in the early development of the body axis and is replaced subsequently by the skull base and vertebrae. Because the remnant notochord resides in these bone structures, chordoma commonly occurs in the midline of the skull base, vertebrae, and sacrum, at frequencies of $32 \%, 32.8 \%$, and $29.2 \%$, respectively. ${ }^{31}$ Generally, chordoma growth is slow, with low histological MIB-1 labeling indices reflecting low mitotic rates. However, complete resection of chordoma is not achievable in most cases because of destruction and infiltration of the surrounding bone tissue.

The current standard treatment for chordoma is maxi-

ABBREVIATIONS $\mathrm{CDNA}=$ complementary DNA; DMSO = dimethyl sulfoxide; EMT = epithelial-mesenchymal transition; $F C=$ fold change; $h E S C=$ human embryonic stem cell; KEGG = Kyoto Encyclopedia of Genes and Genomes; $m$ TOR = mammalian target of rapamycin; PFS = progression-free survival; qRT-PCR = quantitative real-time reverse transcription polymerase chain reaction.

SUBMITTED June 5, 2016. ACCEPTED December 21, 2016.

INCLUDE WHEN CITING Published online July 28, 2017; DOI: 10.3171/2016.12.JNS161444. 
mum safe resection followed by high-dose radiation therapy. Unfortunately, radiation therapy is generally not curative, and there are no effective chemotherapeutic options, so the disease usually follows a clinically malignant course with repeated recurrence. ${ }^{7}$ A recent comprehensive analysis reported a median survival of 6.29 years, and $5-, 10-$, and 20 -year survival rates of $67.6 \%, 39.9 \%$, and $13.1 \%$, respectively. ${ }^{31}$ To improve the prognosis for this life-threatening disease, the development of novel chemotherapeutic approaches is required, including those that target molecules essential for chordoma growth. With this in mind, we examined the Brachyury gene, a key regulator of notochord development, as a potential target for chordoma therapy.

The Brachyury gene, also referred to as the $T$ gene, is located on chromosome $6 \mathrm{q} 27$, and encodes a transcription factor that is essential for the generation of mesoderm and the regulation of mesodermal differentiation to notochord during embryogenesis. ${ }^{18}$ Brachyury is highly and specifically expressed in mesoderm and notochord, and is also overexpressed in chordoma. ${ }^{11,19,30}$ Previous reports showed that Brachyury expression is useful for distinguishing chordoma from other sometimes histologically indistinguishable tumors such as chondrosarcoma, which has a better prognosis. ${ }^{11,19,30}$

Knocking down Brachyury expression in a chordoma cell line suppresses growth in vitro, ${ }^{10}$ and the immunohistochemical detection of Brachyury protein is associated with shorter time to progression in patients with skull base chordoma. ${ }^{14}$ Given its role in mesoderm formation and the various clinical associations, we hypothesized that deregulated Brachyury expression might play a key role in chordoma progression.

The object of this study was to assess Brachyury as a possible molecular target for the treatment of chordoma. First, we examined whether Brachyury expression was correlated with clinical malignancy in skull base chordoma. Second, we investigated the potential mechanisms driving Brachyury overexpression in chordoma, including Brachyury gene copy number aberrations and transcriptional regulators of Brachyury expression. Finally, we discuss the potential of Brachyury, and pathways regulating Brachyury expression, as therapeutic targets for chordoma treatment.

\section{Methods \\ Patient Population}

We analyzed 29 frozen tumor samples resected from 19 patients diagnosed with skull base chordoma at the University of Tokyo Hospital between September 1994 and March 2014. Patient characteristics and clinical histories are presented in Fig. 1. Similar numbers of patients were treated with craniotomy or transnasal-transsphenoidal endoscopic procedures. This study was approved by the $\mathrm{Hu}-$ man Genome, Gene Analysis Research Ethics Committee of the University of Tokyo. Written informed consent was obtained from all patients involved.

\section{Evaluation of Disease Progression}

We used progression-free survival (PFS) as an indicator of clinical malignancy. Overall survival was not considered to be appropriate for evaluating clinical malignancy in our series because only 4 of 19 patients died during the follow-up period, and the duration of the terminal phase appeared to be affected by the temperament and social environment of each patient. The PFS was calculated as the period from the day of surgery to the day when a new enhancing lesion or enlargement of residual tumor was detected by MRI.

\section{Quantitative Real-Time Reverse Transcription Polymerase Chain Reaction}

Brachyury messenger (m)RNA expression was analyzed by quantitative real-time reverse transcription polymerase chain reaction (qRT-PCR), using RNA samples extracted from frozen tumor specimens and a human chordoma cell line. Total RNA was extracted by RNeasy Mini Kit (Qiagen) following the manufacturer's instructions. RNA was considered to be of suitable quality at A260/A230 and A260/A280 ratios of $>1.7$ measured by Nano Vue Plus (GE Healthcare), and RNA integrity numbers $>7.0$ measured by Agilent 2100 bioanalyzer (Agilent Technologies). Complementary DNA (cDNA) was synthesized from $1 \mu \mathrm{g}$ of total RNA using a SuperScript VILO kit (Invitrogen). The qRTPCR was performed using Fast SYBR Green Master Mix (Life Technologies) and a StepOnePlus Real-Time PCR System (Applied Biosystems). Forward and reverse primers were designed from Brachyury exon 4 and 7 sequences, which amplify a 191-bp cDNA fragment (Brachyury forward 5'-TGAGACCCAGTTCATAGCGG-3', reverse 5'-TGCTGGTTCCAGGAAGAAGC-3'). GAPDH primers amplify a 138-bp cDNA fragment and were designed according to previous reports (GAPDH forward 5'-GCACCGTCAAGGCTGAGAAC-3', reverse 5'-TGGTGAAGACGCCAGTGGA-3').,

Aliquots of cDNA were amplified for 40 cycles consisting of 30 seconds of denaturation at $95^{\circ} \mathrm{C}, 30$ seconds of annealing at $60^{\circ} \mathrm{C}$, and 30 seconds of extension at $72^{\circ} \mathrm{C}$. Each PCR was performed in triplicate. The specificity of the amplification products was validated by postamplification melt curve analysis. Expression was calculated by the relative quantitation method in which a standard curve made with a mixture of all samples was used and normalized to GAPDH expression. Gene expression levels were presented relative to those of normal adult whole brain tissue (Clontech Premium RNA \#636530, Takara Bio).

\section{Copy Number Analysis}

We analyzed Brachyury gene copy number in 27 paired tumor and normal blood DNA samples. Tumor DNA was extracted using a QIAamp DNA Mini Kit (Qiagen), and matching blood DNA was extracted using QIAamp DNA Blood Mini Kit (Qiagen) following the manufacturer's instructions. The DNA quality and quantity were evaluated by Nano Vue Plus, and samples with A260/ A230 and A260/A280 ratios > 1.6 were considered suitable for analysis. Copy number was analyzed using TaqMan qPCR Copy Number Assays (Applied Biosystems) and a predesigned TaqMan probe targeting exon 7 of the 


\begin{tabular}{|c|c|c|c|c|c|c|c|c|c|}
\hline $\begin{array}{l}\text { Case } \\
\text { No. }\end{array}$ & Sex & $\begin{array}{c}\text { Sample } \\
\text { No. }\end{array}$ & $\begin{array}{l}\text { Age } \\
\text { (yrs) }\end{array}$ & $\begin{array}{c}\text { Modality of } \\
\text { Surgery }\end{array}$ & $\begin{array}{l}\text { Extent of } \\
\text { Resection }\end{array}$ & $\begin{array}{l}\text { PFS } \\
\text { (days) }\end{array}$ & RNA & DNA & Time Course (days) \\
\hline \multirow[t]{2}{*}{1} & $\mathrm{~F}$ & 1 & 47 & Craniotomy & PR & 1787 & * & * & $\dot{0}_{0}^{\Delta} \quad 500 \quad 1000 \quad 1500 \quad 2000 \quad \underset{2500}{\bullet}$ \\
\hline & & 2 & 54 & Craniotomy & PR & 21 & & $*$ & \\
\hline \multirow[t]{2}{*}{2} & M & 3 & 41 & Craniotomy & GTR & 1104 & * & $*$ & 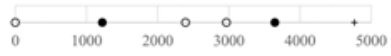 \\
\hline & & 4 & 48 & Endoscopy & GTR & .757 & $*$ & $*$ & \\
\hline \multirow[t]{2}{*}{3} & $\mathrm{~F}$ & 5 & 54 & Craniotomy & PR & 170 & * & $*$ & 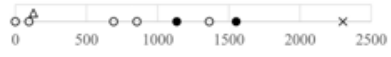 \\
\hline & & 6 & 57 & Craniotomy & PR & 262 & $*$ & $*$ & \\
\hline \multirow[t]{3}{*}{4} & M & 7 & 31 & Craniotomy & GTR & 687 & $*$ & & 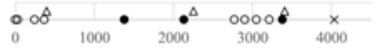 \\
\hline & & 8 & 33 & Craniotomy & GTR & 400 & * & $*$ & \\
\hline & & 9 & 36 & Craniotomy & GTR & 197 & * & $*$ & \\
\hline \multirow[t]{2}{*}{5} & M & 10 & 61 & Craniotomy & PR & 536 & * & $*$ & 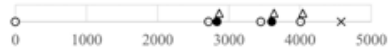 \\
\hline & & 11 & 63 & Craniotomy & PR & 372 & & $*$ & \\
\hline \multirow[t]{2}{*}{6} & $\mathrm{~F}$ & 12 & 26 & Endoscopy & GTR & 101 & $*$ & * & 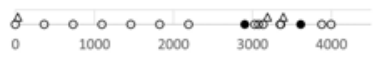 \\
\hline & & 13 & 28 & Endoscopy & GTR & 160 & * & $*$ & \\
\hline \multirow[t]{2}{*}{7} & $\mathrm{~F}$ & 14 & 73 & Endoscopy & GTR & 90 & * & * & 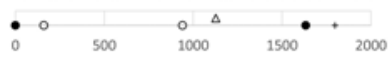 \\
\hline & & 15 & 77 & Endoscopy & GTR & 165 & $*$ & $*$ & \\
\hline 8 & M & 16 & 68 & Endoscopy & PR & 1654 & $*$ & & 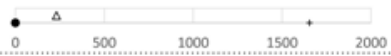 \\
\hline 9 & $\mathrm{~F}$ & 17 & 63 & Endoscopy & PR & 375 & *. & $*$ & 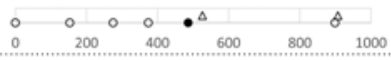 \\
\hline 10 & $\mathrm{M}$ & 18 & 44 & Craniotomy & PR & 161 & * & $*$ & 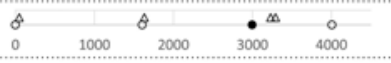 \\
\hline 11 & M & 19 & 35 & Craniotomy & PR & 1462 & $*$ & $*$ & $1000 \quad+1500$ \\
\hline 12 & M & 20 & 61 & Endoscopy & GTR & 223 & $*$ & $*$ & $\begin{array}{lllllll}0^{\Delta} & & & & 0 & A & \\
0 & 500 & 1000 & 1500 & 2000 & 2500\end{array}$ \\
\hline 13 & M & 21 & 36 & Craniotomy & PR & 337 & * & $*$ & 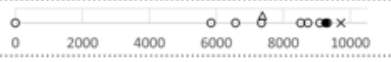 \\
\hline 14 & M & 22 & 68 & Endoscopy & GTR & 2176 & * & $*$ & 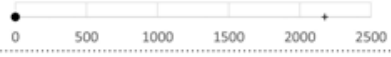 \\
\hline 15 & $\mathrm{~F}$ & 23 & 62 & Craniotomy & GTR & 1273 & $*$ & $*$ & $1000+1500$ \\
\hline \multirow[t]{3}{*}{16} & M & 24 & 73 & Endoscopy & PR & 29 & * & * & 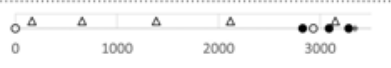 \\
\hline & & 25 & 74 & Endoscopy & GTR & 151 & * & $*$ & \\
\hline & & 26 & 75 & Endoscopy & GTR & 62 & $*$ & $*$ & \\
\hline 17 & M & 27 & 65 & Endoscopy & GTR & 107 & $*$ & $*$ & ${ }_{1500}^{+} \quad 2000$ \\
\hline 18 & $\mathrm{~F}$ & 28 & 36 & Endoscopy & GTR & 132 & * & $*$ & $+{ }_{150}$ \\
\hline 19 & M & 29 & 29 & Endoscopy & $\mathrm{R}$ & 75 & * & * & $:$ \\
\hline
\end{tabular}

FIG. 1. Chart showing characteristics of 19 patients with skull base chordoma. Age denotes the patient's age when the surgery was performed, and PFS consists of the period from the date of surgery to the date when the recurrence was detected. The asterisks indicate that the RNA or DNA was of suitable quality to be analyzed. For the time course, the black circles indicate surgery (analyzed sample); white circles denote other surgeries; triangles represent radiation therapy or Gamma Knife surgery; "x" denotes patient death; and "+" denotes time of latest follow-up. GTR = gross-total resection; PR = partial resection.

Brachyury gene (Hs02212422_cn; Applied Biosystems). To address the reproducibility of the results, we included another TaqMan probe targeting Brachyury exon 6, based on a previous report..$^{13}$ The sequences of the PCR primers and TaqMan probe targeting exon 6 were as follows: forward 5'-GTACTCCCAATGTACGGTTTGTTG-3', reverse 5'-TCAGCAAGTCTAGTCCCGATGAC-3', TaqMan probe, 5'-CTCTGTCATGTCATTCTG-3'. A RNaseP probe (\#4403326; Applied Biosystems) was used as an in- ternal reference for normal diploid copy number in each sample. As additional normal controls, we analyzed blood samples of patients with chondrosarcoma and meningioma who were diploid for the Brachyury gene. The DNA was amplified for 40 cycles consisting of 15 seconds of denaturation at $95^{\circ} \mathrm{C}$, and simultaneous annealing and extension for 60 seconds at $60^{\circ} \mathrm{C}$. Copy numbers were calculated by the $\Delta \Delta \mathrm{Ct}$ method, and $>2.5$ was deemed positive for copy number gain. 


\section{Microarray Analysis}

Microarray analysis was performed at the Contract Development and Manufacturing Center (Takara Bio) using GeneChip Human Genome U133 Plus 2.0 Arrays (Affymetrix, Inc.), which contain more than 54,000 probe sets, representing more than 38,500 genes. The array experiment was performed according to the GeneChip 3'IVT Express Kit User Manual, using $250 \mathrm{ng}$ of total RNA for each sample. To allow comparisons across multiple arrays, gene expression levels were normalized for each array by assigning the average of overall expression levels as 500 .

The expression levels of all analyzed genes were compared between the group with higher Brachyury expression and those with lower Brachyury expression. Fold change (FC) for each gene was calculated as the average of Brachyury expression in the group with high expression/the average in the group with low expression. The $p$ value was calculated using the Student t-test comparing 2 groups.

To assign target genes to signaling pathways, we used the Kyoto Encyclopedia of Genes and Genomes (KEGG) pathway database (http://www.genome.jp/kegg/pathway. $\mathrm{html}$ ). To evaluate the statistical significance of the relationship between a set of target genes and a given pathway, $\mathrm{p}$ values were calculated by Fisher's exact test.

\section{Immunostaining}

Formalin-fixed, paraffin-embedded tumor samples were subjected to antigen retrieval by microwave treatment in sodium citrate buffer ( $\mathrm{pH}$ 6.0), and incubated with primary antibody. After incubation with secondary antibody, samples were treated with 3'3-diaminobenzidine substrate solution and counterstained with hematoxylin. The primary antibodies used were antiphosphorylated S6 ribosomal protein (\#2211; Cell Signaling Technology) and anti-Ki-67 (M7240; Dako). The percentage of cells expressing Ki-67 (Ki-67 labeling index) was evaluated by counting approximately 1000 nuclei per field.

\section{Analysis of the U-CH2 Chordoma Cell Line}

The chordoma cell line U-CH2 was provided by the Chordoma Foundation in July 2014, ${ }^{4}$ and has been described in previous reports. ${ }^{12,16,26,32}$ The characteristics and molecular features of U-CH2 are shown in Supplementary Table 1. To address the effect of PI3K/Akt pathway suppression on Brachyury expression in vitro, $\mathrm{U}-\mathrm{CH} 2$ cells were cultured for 7 days at $37^{\circ} \mathrm{C}$ in $5 \% \mathrm{CO}_{2}$ in a $4: 1$ ratio of IMDM (12440, Invitrogen)/RPMI 1640 (R8758, SigmaAldrich) supplemented with $10 \%$ fetal bovine serum and $100 \mathrm{U} / \mathrm{ml}$ penicillin-streptomycin (15140122, Invitrogen/ Gibco) in 6-well flasks. After serum starvation for 24 hours, PI3K/Akt pathway inhibitors or vehicle (dimethyl sulfoxide [DMSO]) was added to each well. The PI3K inhibitors included $50 \mu$ M LY294002 (\#9901; Cell Signaling Technology), $1 \mu \mathrm{M}$ BEZ235 (\#1281; Axon Medchem), and $0.5 \mu \mathrm{M}$ wortmannin (\#9951; Cell Signaling Technology). Rapamycin (100 nM) (\#9904; Cell Signaling Technology) was used as a mammalian target of rapamycin (mTOR) inhibitor. After 24 hours of incubation, cells in each well were collected, and Brachyury mRNA expression was analyzed by qRT-PCR as described before.

Cell growth was evaluated by WST-1 assay. Briefly, U-CH2 cells were dispensed at 2000 cells per well into 96-well plates and cultured overnight at $37^{\circ} \mathrm{C}$ in $5 \% \mathrm{CO}_{2}$, and the experiment was started 24 hours after the cells were dispensed. For Brachyury suppression, 5 pmol each of Stealth RNAi targeting Brachyury (110425 [Bra1] or 110427 [Bra3]; Invitrogen) were transfected with lipofectamine 2000 (Invitrogen) into each well. Negative Control Medium GC (Nega M, Invitrogen) was used as a control. For PI3K/Akt pathway inhibition experiments, $3 \mathrm{ml}$ of $1 \mu \mathrm{M}$ BEZ235, 0.1 $\mu \mathrm{M}$ BEZ235, or DMSO were added to each well and the medium was changed every day while culturing. Cell number was evaluated using a Premix WST-1 Cell Proliferation Assay Kit (Takara Bio). Absorbance was measured at $440 \mathrm{~nm}$ by using an Infinite 200 Microplate reader (TECAN).

\section{Western Blotting}

Cells were lysed in RIPA buffer containing $50 \mathrm{mM}$

TABLE 1. Upregulated and downregulated pathways in chordomas with higher Brachyury expression

\begin{tabular}{|c|c|c|c|}
\hline KEGG Pathway & $\begin{array}{l}\text { No. of } \\
\text { Genes }\end{array}$ & $\begin{array}{c}p \\
\text { Value }\end{array}$ & Included Genes \\
\hline \multicolumn{4}{|l|}{ Upregulated pathway } \\
\hline $\begin{array}{l}\text { PI3K-Akt signaling } \\
\text { pathway }\end{array}$ & 8 & $0.006^{*}$ & $\begin{array}{l}\text { BCL2L1, CHRM1, ITGA3, } \\
\text { ITGA6, LAMA4, } \\
\text { MDM2, NRAS, RHEB }\end{array}$ \\
\hline Pathways in cancer & 8 & $0.007^{*}$ & $\begin{array}{l}\text { BCL2L1, ITGA3, ITGA6, } \\
\text { LAMA4, MDM2, } \\
\text { NRAS, SLC2A1, STK4 }\end{array}$ \\
\hline Cell cycle & 6 & $0.001^{*}$ & $\begin{array}{c}\text { BUB1, BUB1B, MCM3, } \\
\text { MDM2, ORC6, TTK }\end{array}$ \\
\hline Others & 305 & & \\
\hline Total & 327 & & \\
\hline \multicolumn{4}{|l|}{ Downregulated pathway } \\
\hline Metabolic pathways & 8 & 0.07 & $\begin{array}{c}\text { AGXT, ASPA, CBR3, } \\
\text { CYP2C18, IDUA, } \\
\text { NAT8L, TST, UPB1 }\end{array}$ \\
\hline Pathways in cancer & 8 & 0.44 & $\begin{array}{l}\text { EGFR, GLI3, RASSF5, } \\
\text { RET, RUNX1T1, SUFU, } \\
\text { TCF7L1, TGFB2 }\end{array}$ \\
\hline $\begin{array}{l}\text { Calcium signaling } \\
\text { pathway }\end{array}$ & 7 & $0.01^{*}$ & $\begin{array}{l}\text { CACNA1D, CACNA1, } \\
\text { MYLK, PRKCA, } \\
\text { PRKCG, STIM2, } \\
\text { TACR1 }\end{array}$ \\
\hline $\begin{array}{l}\text { MAPK signaling } \\
\text { pathway }\end{array}$ & 7 & 0.09 & $\begin{array}{l}\text { CACNA1D, CACNA1I, } \\
\text { CACNA2D3, EGFR, } \\
\text { RAP1A, TGFB2, ZAK }\end{array}$ \\
\hline Others & 465 & & \\
\hline Total & 495 & & \\
\hline
\end{tabular}

* Significant at $p<0.05$. 
Tris- $\mathrm{HCl}(\mathrm{pH}$ 8.0), $150 \mathrm{mM} \mathrm{NaCl}, 2 \mathrm{mM}$ EDTA, $1 \%$ NP40, $0.5 \%$ sodium deoxycholate, $0.1 \%$ sodium dodecyl sulfate, and inhibitors of proteases and phosphatases. The lysates were separated on $11 \%$ sodium dodecyl sulfatepolyacrylamide gels and electroblotted onto PVDF membranes (Immuno-Blot PVDF Membrane, Bio-Rad Laboratories). Membranes were blocked in $2 \%$ nonfat milk/ PBST $(0.03 \%$ Tween 20$)$ and probed with anti- $\beta$-actin mouse monoclonal antibody (A3854; Sigma-Aldrich), anti-Brachyury mouse monoclonal antibody (ab140661; Abcam), anti-Akt1/2/3 rabbit polyclonal antibody (sc8312; Santa Cruz Biotechnology), or antiphospho-Akt rabbit monoclonal antibody (\#3787; Cell Signaling Technology). Blots were then incubated with Amersham ECL antimouse IgG peroxidase-linked species-specific whole antibody (NA931; GE Healthcare Life Sciences) or goat anti-rabbit IgG horseradish peroxidase (sc-2004; Santa Cruz Biotechnology) followed by enhanced chemiluminescence detection (\#RPN2232, GE Healthcare), according to the manufacturer's instructions.

\section{Statistical Analysis}

The Student t-test was used for evaluation of probability of the coefficient of correlation, comparing the gene copy number of tumors and blood samples, and comparing gene expression profiles of the 2 groups in microarray analysis. The log-rank test was used for comparing the PFS of the 2 groups. The Wilcoxon rank-sum test was used for comparing Brachyury expression between the 2 groups. The Fisher exact test was used for evaluation of the probability of pathway involvement, and for comparing the positive ratio of phosphorylated S6 ribosomal protein staining. JMP Pro v.11 (SAS Institute) software was used for the statistical analyses. Differences were considered significant at $\mathrm{p}<0.05$.

\section{Results}

\section{Association Between Brachyury Expression and PFS}

An RNA sample of sufficient quality for analysis was obtained from 27 of the 29 specimens (Fig. 1). The average follow-up period was 17.5 months. All chordoma samples expressed Brachyury at higher levels than normal brain tissue, and the relative Brachyury expression level compared with normal brain was $1249 \pm 743$ (average \pm SD). However, the expression levels varied widely between samples (Fig. 2A). A moderate but significant positive correlation between Brachyury expression and positive Ki-67 labeling index was observed $(R=0.47, p=$ 0.014) (Fig. 2B).

To address the association between Brachyury expression and PFS, we divided the specimens into 2 groups based on the average Brachyury expression cutoff value of 1249. The group with higher Brachyury expression contained 11 samples, and the group with lower expression contained 16 samples. We compared the PFS of the 2 groups using Kaplan-Meier curves. The group with higher Brachyury expression showed significantly shorter PFS than the group with lower expression (median PFS 5 months vs 13 months, respectively; $\mathrm{p}=0.03$ ) (Fig. 2C).

\section{Copy Number Analysis of the Brachyury Gene}

The average copy number of the tumor DNA was 2.6 $\pm 0.6( \pm \mathrm{SD})$, and 12 of $27(44 \%)$ tumors had a gain of more than 2.5 copies. In contrast, no copy number gain was observed in the matched blood DNA $(2.0 \pm 0.1)$ (Fig. 3A). There was a significant difference between Brachyury gene copy number in tumors and blood samples $(\mathrm{p}<$ 0.001 ). To address the reproducibility of the result, a gene copy number analysis was performed using another primer set targeting exon 6 of the Brachyury gene. These data were strongly correlated with the original data $(\mathrm{R}=0.76$, $\mathrm{p}<0.001$ ).

There was a significant positive correlation between Brachyury expression and copy number $(\mathrm{R}=0.61$, $\mathrm{p}<$ 0.001 ), suggesting that the copy number gain led to Brachyury overexpression (Fig. 3B). The Brachyury expression levels in the tumors with copy number gain were significantly higher than those of tumors with normal copy number $(\mathrm{p}=0.008)$. Therefore, somatic Brachyury gene copy number gain appears to be a mechanism driving Brachyury overexpression in at least some chordomas.

\section{Regulation of Brachyury Transcription}

To identify other genes with expression patterns that were significantly correlated with Brachyury expression, we performed whole transcriptome microarray analysis of 4 samples with higher Brachyury expression (sample numbers 12, 20, 25, 29) and 4 samples with lower Brachyury expression (sample numbers 8, 14, 18, 19) (Fig. 1). Brachyury expression levels in the 2 groups were significantly different (the average \pm SD was $2384 \pm 339$ in the higher group, and $435 \pm 431$ in lower group; $p=0.03$ ). A volcano plot including all probe sets was constructed by plotting the $-\log _{10} \mathrm{p}$ value on the $\mathrm{y}$-axis and the $\log _{2} \mathrm{FC}$ on the x-axis (see Supplementary Fig. S1).

We first extracted the probe sets with $\mathrm{p}<0.05$ and absolute $\mathrm{FC}>2$. On this basis, there were 327 upregulated and 495 downregulated genes in the higher Brachyury expression group. Interrogation of the KEGG pathway database revealed that the "PI3K/Akt pathway" was the most significantly associated gene network $(\mathrm{p}=0.006)$, including 8 upregulated genes (BCL2L1, CHRM1, ITGA3, ITGA6, LAMA4, MDM2, NRAS, and RHEB) (Table 1), which are all known to function as activators of the PI3K/ Akt cascade. Other networks linked to the upregulated genes according to the KEGG database were "pathways in cancer" and "cell cycle." The "calcium signaling pathway" was the network most significantly associated with the downregulated genes. When stricter criteria were applied ( $\mathrm{p}<0.01, \mathrm{FC}>2$ ), 68 genes were significantly upregulated and 87 downregulated (Supplementary Table 2 ). Under the stricter criteria, "PI3K/Akt pathway" was still the most significantly associated network $(\mathrm{p}=0.03)$, including 4 upregulated genes (CHRM1, ITGA3, MDM2, and $R H E B$ ).

\section{Activation of the PI3K/Akt Pathway}

To follow up the microarray data, we examined whether the PI3K/Akt pathway was indeed activated in chor- 

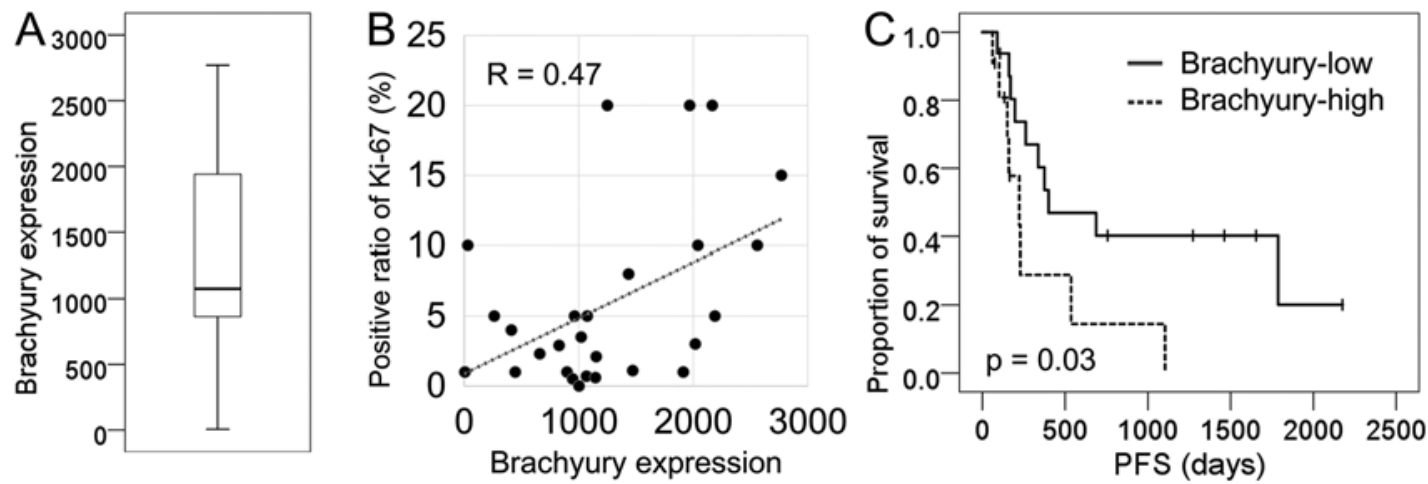

FIG. 2. A: Distribution of Brachyury expression levels in all chordoma specimens $(n=27)$ measured by qRT-PCR. Box plot shows maximum, upper quartile, median, lower quartile, and minimum. Expression levels are relative to that of normal brain. B: The relationship between Brachyury gene expression and Ki-67 labeling index. The coefficient of correlation was 0.47. C: Kaplan-Meier curves of PFS comparing the Brachyury high-expression and Brachyury low-expression groups. The Brachyury high-expression group had significantly shorter PFS than the Brachyury low-expression group $(p=0.03)$.

doma with higher Brachyury expression. As a marker of PI3K/Akt pathway activation, we assessed the phosphorylation status of the S6 ribosomal protein by using immunohistochemistry. ${ }^{2,34}$ Cells exhibiting cytoplasmic staining were considered positive (Fig. 3C). There was a significant difference in the number of phosphorylated S6 ribosomal protein-positive specimens in the higher Brachyury group (9 in 10; 90\%) compared with in the lower Brachyury group (6 in 16; 38\%) $(\mathrm{p}=0.014)$ (Table 2). These findings were consistent with PI3K/Akt pathway activation in chordomas with higher Brachyury expression.

Next, to see whether Brachyury gene copy number was linked to PI3K/Akt pathway activation, we assessed the correlation between phosphorylated S6 ribosomal protein positivity and Brachyury gene copy number in the 2 groups. Seven of the 12 specimens with copy number gain and 7 of the 12 without copy number gain were phosphorylated S6 ribosomal protein-positive. The lack of a significant association between copy number gain and PI3K/ Akt pathway activation indicated that PI3K/Akt activation was not the consequence of Brachyury gene amplification, which is associated with higher Brachyury expression. Instead, these data suggest that the PI3K/Akt pathway is driving Brachyury expression, independent of Brachyury gene copy number.

\section{Brachyury Is Upregulated by PI3K/Akt Signaling and Promotes Chordoma Cell Growth}

To further evaluate the relationship between PI3K/ Akt signaling and Brachyury expression, we used the drugs LY294002, BEZ235, and wortmannin to inhibit the activity of the PI3K/Akt pathway in the chordoma cell line U-CH2. Suppression of the PI3K/Akt pathway by BEZ235 was confirmed by reduced phospho-Akt expression (Fig. 4A). Suppression of PI3K with LY294002, BEZ235, or wortmannin resulted in decreases in Brachyury expression of $68 \%, 44 \%$, and $32 \%$, respectively (Fig. 4B). Treatment with LY294002 and BEZ235 significantly suppressed Brachyury expression ( $\mathrm{p}=0.001$ and 0.006, respectively), while suppression of mTOR with rapamycin decreased expression marginally (approximately 20\%).
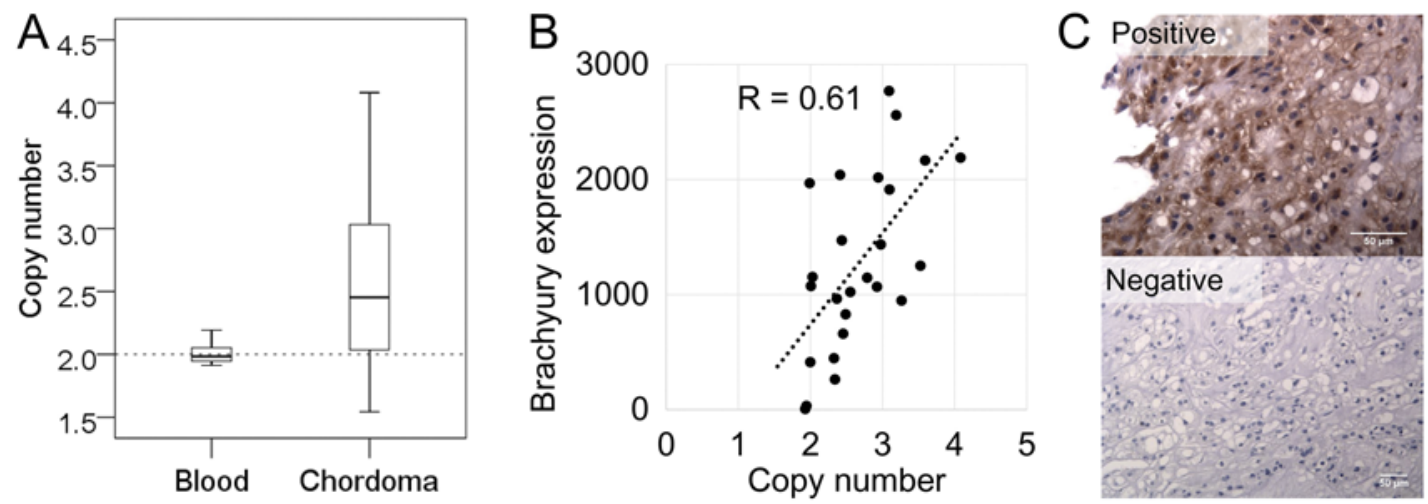

FIG. 3. A: TaqMan Copy Number Assays targeting exon 7 of the Brachyury gene revealed that the Brachyury gene copy number in chordoma was significantly higher than in matched normal blood samples $(n=27, p<0.001)$. B: There was a significant positive correlation between Brachyury gene copy number (exon 7) and Brachyury expression $(R=0.61, p<0.001)$. C: Representative positive and negative immunostaining of phosphorylated $\mathrm{S} 6$ ribosomal protein is shown. The samples containing cells with stained cytoplasm were considered positive. 
TABLE 2. Correlation between Brachyury expression and PI3K/ Akt pathway activation

\begin{tabular}{|c|c|c|}
\hline \multirow{2}{*}{$\begin{array}{c}\text { Phospho-S6 } \\
\text { Ribosomal Protein }\end{array}$} & \multicolumn{2}{|c|}{ Brachyury Level } \\
\hline & High* & Low \\
\hline Positive & 9 & 6 \\
\hline Negative & 1 & 10 \\
\hline
\end{tabular}

* One sample in this group could not be evaluated with immunohistochemistry.

Brachyury protein levels were decreased when the U-CH2 cell line was treated with BEZ235 (Fig. 4A). In addition, both Brachyury knockdown (Fig. 4C and D) and inhibition of the PI3K/Akt pathway with BEZ235 (Fig. 4E) markedly suppressed the growth of U-CH2 chordoma cells. These results suggest that Brachyury expression is upregulated by PI3K/Akt pathway activation, and inhibition of the pathway leads to suppression of chordoma cell growth.

\section{Discussion}

We demonstrated that Brachyury expression was a prog- nostic factor in chordoma and that somatic Brachyury gene copy number gain and PI3K/Akt pathway activation are probably mechanisms that drive Brachyury overexpression (Fig. 5). There are a few earlier studies addressing Brachyury expression and the prognosis of chordoma. Kitamura et al. ${ }^{14}$ reported significantly shorter PFS in Brachyury-positive chordoma based on qualitative immunohistochemical evaluation of Brachyury expression. Consistent with this, we examined Brachyury mRNA expression quantitatively by qRT-PCR, and confirmed that Brachyury expression levels varied among samples and were associated with prognosis. A relationship between Brachyury expression and prognosis was also reported in other neoplasms such as colorectal, breast, prostate, and lung cancers. ${ }^{20-22,25}$ In these other cancers, Brachyury was considered to promote epithelial-mesenchymal transition (EMT), leading to a worse prognosis in general. Given that chordoma has both epithelial and mesenchymal characteristics, we also looked into the possible relationship between Brachyury expression and EMT in our transcriptome microarray data. However, expression levels of both E-cadherin and Snail, known markers of EMT, were not significantly different
A
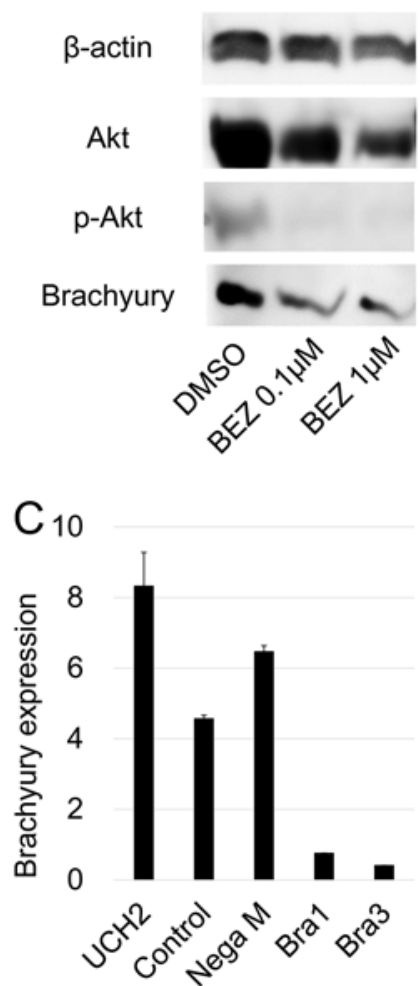
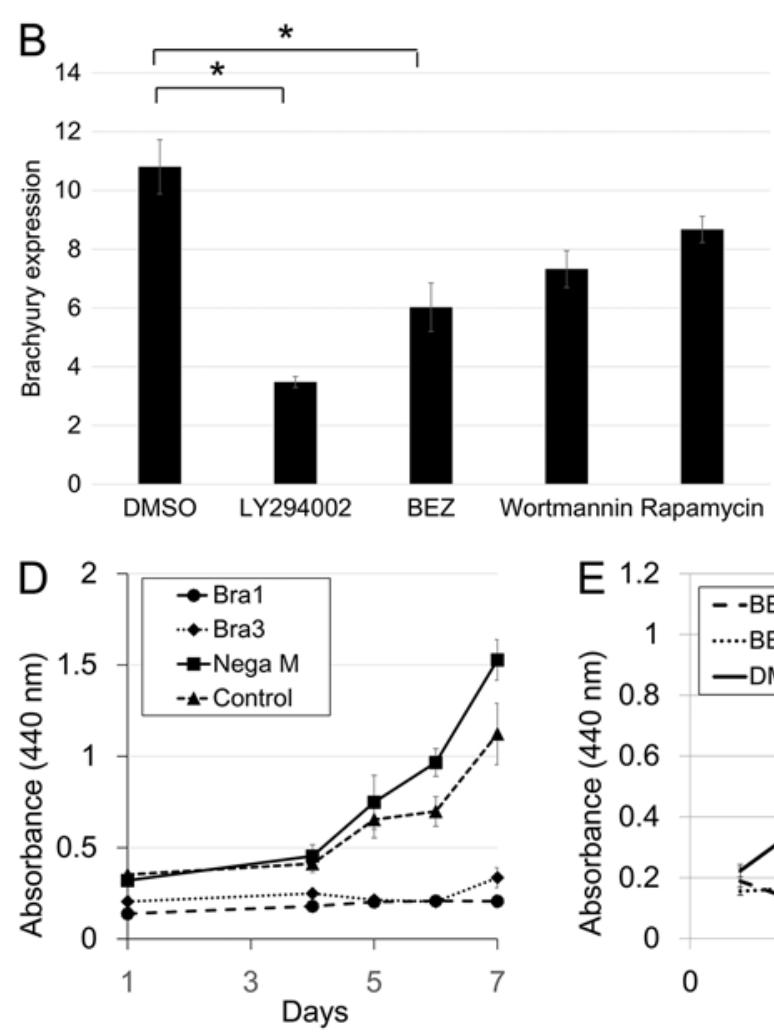

FIG. 4. Effect of PI3K pathway inhibition on Brachyury expression and chordoma cell growth. A: Western blot analysis of Brachyury, phospho-Akt (p-Akt), Akt, or $\beta$-actin in U-CH2 cells treated with $0.1 \mu \mathrm{M} B E Z 235,1 \mu \mathrm{M} \mathrm{BEZ235}$, or DMSO. The inhibition of the PI3K/Akt pathway by BEZ235 was confirmed by suppression of phospho-Akt expression. Phospho-Akt and Brachyury expression were decreased after inhibition of the PI3K/Akt pathway by BEZ235. B: The chordoma cell line U-CH2 was treated with PI3K inhibitors (LY294002, BEZ235, or wortmannin), mTOR inhibitor (rapamycin), or vehicle (DMSO) for 24 hours. Brachyury expression was measured by qRT-PCR, and expression levels were compared with control $\left({ }^{*} p<0.05\right)$. C: The U-CH2 cell line was treated with lipofectamine 2000 (control), 5 pmol of small interfering RNA targeting Brachyury (Bra1 or Bra3), or Negative Control Medium GC (Nega M). Suppression of Brachyury expression was confirmed by qRT-PCR. D: The U-CH2 cell growth curves were evaluated by WST-1 assay. Cell growth decreased in response to Brachyury suppression. E: Cell growth curves of U-CH2 cells treated with $0.1 \mu \mathrm{M}$ BEZ235, $1 \mu \mathrm{M}$ BEZ235, or DMSO evaluated by WST-1 assay. Maximum significant cell growth inhibition was achieved with $0.1 \mu \mathrm{M}$ BEZ235. Error bars in each figure show the standard deviation. 


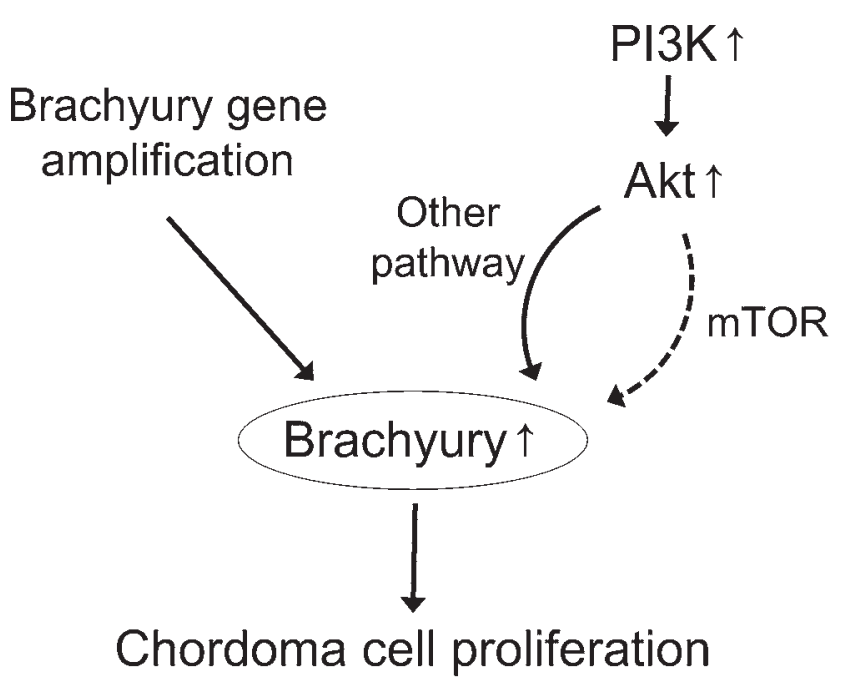

FIG. 5. Schematic depiction of the interplay between Brachyury copy number gain, Brachyury overexpression, and activation of the PI3K/Akt pathway in chordoma pathogenesis.

between the higher and lower Brachyury expression groups (p values 0.49 and 0.71 , respectively; Student t-test). Thus, based on these data, EMT does not appear to be linked to Brachyury expression in chordoma.

Somatic copy number gain is observed frequently in various types of cancers and is considered to be an important mechanism contributing to the upregulation of oncogene expression. ${ }^{3}$ Several previous reports demonstrated Brachyury gene copy number gain in chordoma. Presneau et al. ${ }^{24}$ reported Brachyury gene copy number gain in $7 \%$ of 181 sporadic chordomas, and $38 \%$ had polysomy of chromosome 6. Similarly, other reports indicated that in $20 \%-30 \%$ of chordoma cases there was Brachyury gene copy number gain. ${ }^{8,14,15}$ In addition, germline duplication of the Brachyury gene was reported in patients with familial chordoma. ${ }^{33}$ Overall, these results indicate that Brachyury overexpression plays an important role in chordoma oncogenesis.

The PI3K/Akt pathway has been linked to chordoma pathogenesis by several groups. Presneau et al. ${ }^{23}$ detected expression of phosphorylated S6 ribosomal protein in $22 \%$ of 50 chordoma samples by immunohistochemistry. Schwab et al. ${ }^{27}$ showed activation of the PI3K/Akt pathway by Western blot, and demonstrated that suppression of the pathway by an mTOR inhibitor, PI-103, resulted in growth inhibition in chordoma cell lines. Tamborini et al. ${ }^{29}$ also reported activation of both the PI3K/Akt and RAS/ MAPK pathways in chordoma. Our data expand on these observations and identify a link between PI3K/Akt pathway activation and Brachyury overexpression that has not been described previously. To look for possible functional links between Brachyury and the PI3K/Akt pathway, we experimentally inhibited the PI3K/Akt pathway in a chordoma cell line and observed downregulation of Brachyury expression. The results indicated that oncogenic Brachyury expression was linked not only to gene amplification but also to PI3K/Akt pathway activation, consistent with the fact that higher Brachyury expression was observed in some skull base chordomas without Brachyury gene amplification. It is possible that aberrant PI3K/Akt pathway activation might have induced genomic instability that subsequently resulted in Brachyury gene copy number gain. However, our data suggest that this is unlikely because there was no obvious relationship between PI3K/ Akt pathway activation and copy number gain in our clinical samples.

Two different PI3K inhibitors, LY294002 and BEZ235, significantly suppressed Brachyury expression in the $\mathrm{U}-\mathrm{CH} 2$ cell line, indicating that Brachyury transcription is indeed regulated by the PI3K pathway. Wortmannin, another PI3K inhibitor, also suppressed Brachyury expression, but the difference was not statistically significant, possibly because wortmannin is more unstable than LY294002 in aqueous solution. Similarly, a trend toward suppression of Brachyury expression was also observed using rapamycin, an mTOR inhibitor. These results indicate that the regulation of Brachyury expression by PI3K/ Akt signaling is not only mediated through the mTOR pathway but also through other factors downstream of Akt, suggesting that while targeted inhibition of mTOR could be effective, inhibition of upstream signaling might be more efficient for the treatment of chordoma.

The activity of PI3K/Akt has been linked to the maintenance of human embryonic stem cell (hESC) pluripotency, and blockage of the pathway accelerated hESC differentiation and induction of mesodermal markers, including Brachyury. ${ }^{28}$ These data suggest that PI3K/Akt activity may also be important for maintaining the undifferentiated state of other immature tissues, including notochord. However, in such a scenario, Brachyury expression would be expected to decrease in response to inhibition of the PI3K/ Akt pathway, in contrast to the case of hESCs, because Brachyury expression in the notochord is lost during differentiation. Chordoma is thought to originate from notochord cells, and induction of differentiation in chordoma may be the underlying mechanism for downregulation of Brachyury expression caused by PI3K/Akt pathway inhibition.

A remaining question is what causes aberrant $\mathrm{PI} 3 \mathrm{~K} / \mathrm{Akt}$ pathway activation in some chordomas. In the 8 samples analyzed by microarray, 5 (4 samples from the Brachyury high-expression group and 1 from the Brachyury low-expression group) were positive for phosphorylated S6 ribosomal protein staining, indicative of activation of the PI3K/ Akt pathway. The results of microarray analysis showed that candidate upstream genes that can activate the PI3K/ Akt pathway, such as EGFR, FGFR, PDGFR, VEGFR, $M E T$, and $I G F I R$, were not significantly upregulated in the chordomas with higher Brachyury expression $(\mathrm{p}=0.23$, $0.13,0.36,0.46,0.42$, and 0.38 , respectively) or in the chordomas positive for phosphorylated S6 ribosomal protein expression ( $\mathrm{p}=0.24,0.12,0.45,0.87,0.09$, and 0.47 , respectively). Our preliminary exome sequence analysis did not identify additional mutations (e.g., PIK3CA mutation) that might be responsible for pathway activation (unpublished data). Further study will be necessary to comprehensively address this issue.

Based on our results, we propose that the Brachyury gene, and genes encoding molecules involved in PI3K/Akt pathway activation, can be considered as chordoma oncogenes and, as such, represent new therapeutic targets for 
the disease. Although drugs targeting Brachyury have not yet been developed, the immunotherapeutic targeting of Brachyury has been reported. Palena et al. ${ }^{20}$ successfully established Brachyury-specific cytotoxic T cells, and demonstrated targeted cell killing in which a lung cancer cell line expressing Brachyury was used. ${ }^{25}$ Importantly, the $\mathrm{PI} 3 \mathrm{~K} / \mathrm{Akt} / \mathrm{mTOR}$ pathway can be effectively targeted by existing agents such as temsirolimus and everolimus, and our data provide some grounds for optimism that a Phase II study currently under way in Italy, in which chordomas are being treated with imatinib and everolimus, will yield encouraging results.

\section{Conclusions}

We demonstrated that increased Brachyury expression was associated with a worse prognosis for skull base chordoma and that the overexpression was likely to be caused by somatic Brachyury gene copy number gain. Activation of the PI3K/Akt pathway also upregulated Brachyury expression and promoted chordoma cell growth in vitro. Therefore, Brachyury, or molecules involved in PI3K/Akt pathway activation upstream of Brachyury, may represent important new targets for chordoma treatment.

\section{Acknowledgments}

This work was supported in part by the Japan Society for the Promotion of Science (JSPS) KAKENHI Grant Number JP23390343, JP26293321, and JP23134501 (A.M.). We are grateful to the patients for donating their tissue for research, and we acknowledge the excellent technical assistance of Reiko Matsuura and Yuka Takahashi at the laboratory of the University of Tokyo. We thank the Chordoma Foundation for providing the cell line $\mathrm{U}-\mathrm{CH} 2$.

\section{References}

1. Akiyama K, Chen C, Wang D, Xu X, Qu C, Yamaza T, et al: Mesenchymal-stem-cell-induced immunoregulation involves FAS-ligand-/FAS-mediated T cell apoptosis. Cell Stem Cell 10:544-555, 2012

2. Bahrami-B F, Ataie-Kachoie P, Pourgholami MH, Morris DL: p70 Ribosomal protein S6 kinase (Rps6kb1): an update. J Clin Pathol 67:1019-1025, 2014

3. Beroukhim R, Mermel CH, Porter D, Wei G, Raychaudhuri $\mathrm{S}$, Donovan J, et al: The landscape of somatic copy-number alteration across human cancers. Nature 463:899-905, 2010

4. Brüderlein S, Sommer JB, Meltzer PS, Li S, Osada T, Ng D, et al: Molecular characterization of putative chordoma cell lines. Sarcoma 2010:630129, 2010

5. Chambers KJ, Lin DT, Meier J, Remenschneider A, Herr M, Gray ST: Incidence and survival patterns of cranial chordoma in the United States. Laryngoscope 124:1097-1102, 2014

6. Di Maio S, Rostomily R, Sekhar LN: Current surgical outcomes for cranial base chordomas: cohort study of 95 patients. Neurosurgery 70:1355-1360, 2012

7. Fagundes MA, Hug EB, Liebsch NJ, Daly W, Efird J, Munzenrider JE: Radiation therapy for chordomas of the base of skull and cervical spine: patterns of failure and outcome after relapse. Int J Radiat Oncol Biol Phys 33:579-584, 1995

8. Hallor KH, Staaf J, Jönsson G, Heidenblad M, Vult von Steyern F, Bauer HC, et al: Frequent deletion of the CDKN2A locus in chordoma: analysis of chromosomal imbalances using array comparative genomic hybridisation. Br J Cancer 98:434-442, 2008

9. Hong LZ, Wei XW, Chen JF, Shi Y: Overexpression of peri- ostin predicts poor prognosis in non-small cell lung cancer. Oncol Lett 6:1595-1603, 2013

10. Hsu W, Mohyeldin A, Shah SR, ap Rhys CM, Johnson LF, Sedora-Roman NI, et al: Generation of chordoma cell line JHC7 and the identification of Brachyury as a novel molecular target. J Neurosurg 115:760-769, 2011

11. Jambhekar NA, Rekhi B, Thorat K, Dikshit R, Agrawal M, Puri A: Revisiting chordoma with brachyury, a "new age" marker: analysis of a validation study on 51 cases. Arch Pathol Lab Med 134:1181-1187, 2010

12. Karikari IO, Gilchrist CL, Jing L, Alcorta DA, Chen J, Richardson WJ, et al: Molecular characterization of chordoma xenografts generated from a novel primary chordoma cell source and two chordoma cell lines. J Neurosurg Spine 21:386-393, 2014

13. Kelley MJ, Shi J, Ballew B, Hyland PL, Li WQ, Rotunno M, et al: Characterization of $\mathrm{T}$ gene sequence variants and germline duplications in familial and sporadic chordoma. Hum Genet 133:1289-1297, 2014

14. Kitamura Y, Sasaki H, Kimura T, Miwa T, Takahashi S, Kawase T, et al: Molecular and clinical risk factors for recurrence of skull base chordomas: gain on chromosome $2 p$, expression of brachyury, and lack of irradiation negatively correlate with patient prognosis. J Neuropathol Exp Neurol 72:816-823, 2013

15. Le LP, Nielsen GP, Rosenberg AE, Thomas D, Batten JM, Deshpande V, et al: Recurrent chromosomal copy number alterations in sporadic chordomas. PLoS One 6:e18846, 2011

16. Mathios D, Ruzevick J, Jackson CM, Xu H, Shah S, Taube JM, et al: PD-1, PD-L1, PD-L2 expression in the chordoma microenvironment. J Neurooncol 121:251-259, 2015

17. McMaster ML, Goldstein AM, Bromley CM, Ishibe N, Parry DM: Chordoma: incidence and survival patterns in the United States, 1973-1995. Cancer Causes Control 12:1-11, 2001

18. Nibu Y, José-Edwards DS, Di Gregorio A: From notochord formation to hereditary chordoma: the many roles of Brachyury. BioMed Res Int 2013:826435, 2013

19. Oakley GJ, Fuhrer K, Seethala RR: Brachyury, SOX-9, and podoplanin, new markers in the skull base chordoma vs chondrosarcoma differential: a tissue microarray-based comparative analysis. Mod Pathol 21:1461-1469, 2008

20. Palena C, Polev DE, Tsang KY, Fernando RI, Litzinger M, Krukovskaya LL, et al: The human T-box mesodermal transcription factor Brachyury is a candidate target for Tcell-mediated cancer immunotherapy. Clin Cancer Res 13:2471-2478, 2007

21. Palena C, Roselli M, Litzinger MT, Ferroni P, Costarelli L, Spila A, et al: Overexpression of the EMT driver brachyury in breast carcinomas: association with poor prognosis. J Natl Cancer Inst 106:dju054, 2014

22. Pinto F, Pértega-Gomes N, Pereira MS, Vizcaíno JR, Monteiro P, Henrique RM, et al: T-box transcription factor brachyury is associated with prostate cancer progression and aggressiveness. Clin Cancer Res 20:4949-4961, 2014

23. Presneau N, Shalaby A, Idowu B, Gikas P, Cannon SR, Gout I, et al: Potential therapeutic targets for chordoma: PI3K/ AKT/TSC1/TSC2/mTOR pathway. Br J Cancer 100:14061414,2009

24. Presneau N, Shalaby A, Ye H, Pillay N, Halai D, Idowu B, et al: Role of the transcription factor $\mathrm{T}$ (brachyury) in the pathogenesis of sporadic chordoma: a genetic and functionalbased study. J Pathol 223:327-335, 2011

25. Roselli M, Fernando RI, Guadagni F, Spila A, Alessandroni J, Palmirotta R, et al: Brachyury, a driver of the epithelialmesenchymal transition, is overexpressed in human lung tumors: an opportunity for novel interventions against lung cancer. Clin Cancer Res 18:3868-3879, 2012

26. Scheil-Bertram S, Kappler R, von Baer A, Hartwig E, Sarkar 
M, Serra M, et al: Molecular profiling of chordoma. Int J Oncol 44:1041-1055, 2014

27. Schwab J, Antonescu C, Boland P, Healey J, Rosenberg A, Nielsen P, et al: Combination of PI3K/mTOR inhibition demonstrates efficacy in human chordoma. Anticancer Res 29:1867-1871, 2009

28. Singh AM, Reynolds D, Cliff T, Ohtsuka S, Mattheyses AL, Sun Y, et al: Signaling network crosstalk in human pluripotent cells: a Smad2/3-regulated switch that controls the balance between self-renewal and differentiation. Cell Stem Cell 10:312-326, 2012

29. Tamborini E, Virdis E, Negri T, Orsenigo M, Brich S, Conca $\mathrm{E}$, et al: Analysis of receptor tyrosine kinases (RTKs) and downstream pathways in chordomas. Neuro Oncol 12:776789,2010

30. Vujovic S, Henderson S, Presneau N, Odell E, Jacques TS, Tirabosco R, et al: Brachyury, a crucial regulator of notochordal development, is a novel biomarker for chordomas. J Pathol 209:157-165, 2006

31. Walcott BP, Nahed BV, Mohyeldin A, Coumans JV, Kahle KT, Ferreira MJ: Chordoma: current concepts, management, and future directions. Lancet Oncol 13:e69-e76, 2012

32. Xia M, Huang R, Sakamuru S, Alcorta D, Cho MH, Lee DH, et al: Identification of repurposed small molecule drugs for chordoma therapy. Cancer Biol Ther 14:638-647, 2013

33. Yang XR, Ng D, Alcorta DA, Liebsch NJ, Sheridan E, Li S, et al: T (brachyury) gene duplication confers major susceptibility to familial chordoma. Nat Genet 41:1176-1178, 2009

34. Zhang L, Wang H, Xu J, Zhu J, Ding K: Inhibition of cathep$\sin \mathrm{S}$ induces autophagy and apoptosis in human glioblastoma cell lines through ROS-mediated PI3K/AKT/mTOR/ p70S6K and JNK signaling pathways. Toxicol Lett 228:248259,2014

\section{Disclosures}

The authors report no conflict of interest concerning the materials or methods used in this study or the findings specified in this paper.

\section{Author Contributions}

Conception and design: Mukasa, Otani. Acquisition of data: Otani, Shin, Omata. Analysis and interpretation of data: Mukasa, Otani, Omata, Takayanagi, Tanaka. Drafting the article: Mukasa, Otani. Critically revising the article: Mukasa, Otani, Ueki.

Reviewed submitted version of manuscript: Mukasa, Otani, Shin, Ueki, Saito. Approved the final version of the manuscript on behalf of all authors: Mukasa. Statistical analysis: Mukasa, Otani. Administrative/technical/material support: Mukasa, Saito. Study supervision: Mukasa, Saito.

\section{Supplemental Information}

Online-Only Content

Supplemental material is available with the online version of the article.

Supplementary Tables 1 and 2 and Supplementary Fig. S1. https://thejns.org/doi/suppl/10.3171/2016.12.JNS161444.

\section{Correspondence}

Akitake Mukasa, Department of Neurosurgery, Graduate School of Medicine, The University of Tokyo, 7-3-1 Hongo, Bunkyo-ku, Tokyo 113-8655, Japan. email: mukasa-nsu@umin.ac.jp. 